\title{
PRODUÇÃO DE BIOSSURFACTANTE POR LEVEDURA
}

Gizele Cardoso Fontes, Priscilla Filomena Fonseca Amaral e Maria Alice Zarur Coelho*

Departamento de Engenharia Bioquímica, Escola de Química, Universidade Federal do Rio de janeiro, CT, Bl. E, 21949-900 Rio de Janeiro, RJ, Brasil

Recebido em 18/8/07; aceito em 24/4/08; publicado na web em 16/10/08

BIOSURFACTANTS PRODUCTION BY YEASTS. Biosurfactants are molecules extracellularly produced by bacteria, yeast and fungi that have significant interfacial activity properties. This review focuses on relevant parameters that influence biosurfactant production by yeasts. Many works have investigated the optimization of yeast biosurfactant production, mainly within the last decade, revealing that the potential of such microorganisms is not well explored in the industrial field. The main points to increase the process viability lays on the reduction of the production costs and enhancement of biosynthesis efficiency through optimization the culture conditions (carbon and nitrogen source, $\mathrm{pH}$, aeration, speed agitation) and the selection of inexpensive medium components.

Keywords: biosurfactants; yeast; surface-active compounds.

\section{INTRODUÇÃ̃o}

Vários microorganismos possuem capacidade de produzir moléculas com atividade interfacial. ${ }^{1}$ Nas últimas décadas tem-se aumentado o interesse em identificar e isolar novos microorganismos produtores de moléculas tenso-ativas que apresentem boas características surfactantes, como baixa concentração micelar crítica (CMC), baixa toxicidade, alta atividade de emulsificação, dentre outras. ${ }^{2}$

A maioria dos biossurfactantes microbianos relatados na literatura é de origem bacteriana. As bactérias produtoras mais reportadas são dos gêneros: Pseudomonas sp., Acinetobacter sp., Bacillus sp. e Arthrobacter sp.. ${ }^{3}$ Entretanto, a grande maioria dos biossurfactantes de origem bacteriana não é adequada para utilização na indústria alimentícia, devido a sua possível natureza patogênica. ${ }^{4}$

As leveduras também têm sido estudadas para a produção de emulsificadores. Entre as leveduras, espécies de Candida e Yarrowia têm sido largamente estudadas e empregadas com sucesso na produção de biossurfactanes. A Tabela 1 apresenta as espécies de levedura mais estudadas e os respectivos biossurfactantes produzidos.

Uma grande vantagem do uso de leveduras reside no status GRAS (generally regarded as safe) que muitas delas apresentam, como Yarrowia lipolytica, Saccharomyces cerevisiae e Kluyveromyces lactis. Organismos com status GRAS não apresentam riscos de toxicidade e patogenicidade, o que permite sua utilização para aplicações nas indústrias de alimentos e farmacêutica. ${ }^{5}$

Alguns microorganismos podem produzir biossurfactantes quando crescem em diferentes substratos, variando desde carboidratos até hidrocarbonetos. $\mathrm{O}$ uso de diferentes fontes de carbono altera a estrutura dos biossurfactantes produzidos e, conseqüentemente, suas propriedades emulsificantes. Estas mudanças podem ser benéficas quando se desejam propriedades específicas para uma aplicação direcionada. ${ }^{26}$ Diversos são os estudos realizados por vários autores ${ }^{18,27,28}$ na produção de biossurfactantes, envolvendo propriedades físico-químicas.

A maioria dos biossurfactantes é geralmente produzida quando as culturas alcançam a fase estacionária de crescimento. ${ }^{29}$ Porém algumas espécies podem apresentar pequena produção durante a fase exponencial de crescimento. Exemplos de perfis de produção de

*e-mail: alice@eq.ufrj.br bioemulsificante pelas leveduras C. lipolytica IA $1055^{30}$ e Y. lipolyitica IMUFRJ 50682, ${ }^{18}$ são apresentados na Figura 1. Apesar da produção de bioemulsificante por Y. lipolytica IMUFRJ 50682 ocorrer durante a fase exponencial de crescimento, a atividade de emulsificação mais significativa ocorreu durante a fase estacionária.

Dada a relevância industrial das leveduras, este trabalho tem por objetivo revisar a influência de diferentes parâmetros na produção de biossurfactantes por este grupo microbiano, demonstrando o seu potencial ainda não totalmente explorado. Restrições relacionadas aos custos de produção também são consideradas.

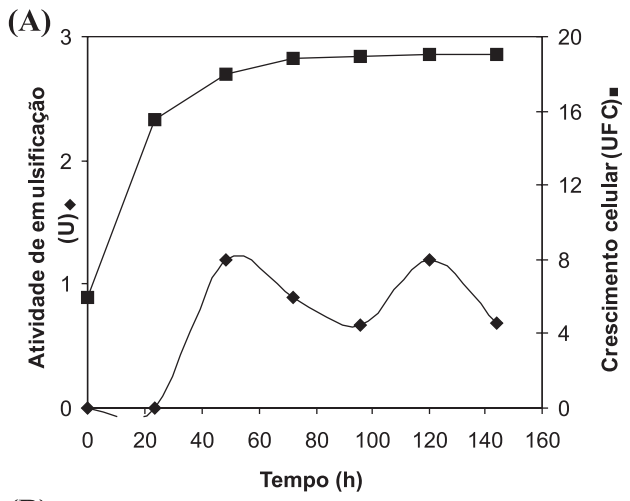

(B)

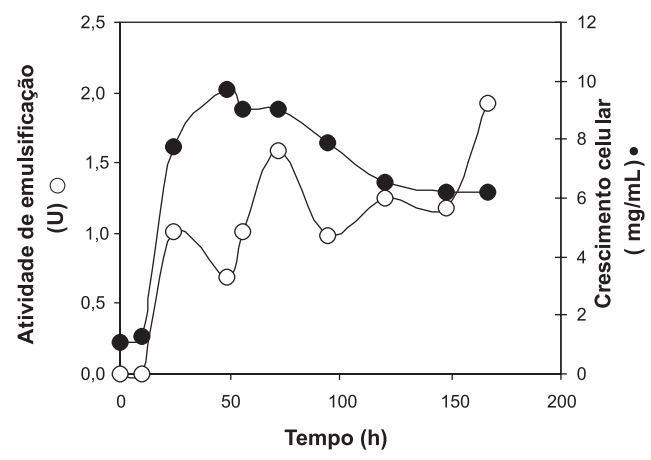

Figura 1. Perfil da produção de bioemulsificante pelas leveduras $C$. lipolytica IA 1055 (A) e Y. lipolyitica IMUFRJ 50682 (B) 
Tabela 1. Principais espécies de levedura produtoras de biossurfactantes

\begin{tabular}{|c|c|c|}
\hline Tipo de biossurfactante & Microorganismo produtor & Ref. \\
\hline \multirow[t]{2}{*}{ Manoproteína } & Kluyveromyces marxianus & 6 \\
\hline & Saccharomyces cerevisiae & 7 \\
\hline \multirow[t]{4}{*}{ Soforolipídeos } & Wickerhamiella domercqiae & 8 \\
\hline & Candida bombicola & 9 \\
\hline & Torulopis petrophilum & 10 \\
\hline & Candida bogorienses & 11 \\
\hline \multirow[t]{8}{*}{$\begin{array}{l}\text { Manosileritritol - } \\
\text { lipídeos }\end{array}$} & Candida antarctica & 12 \\
\hline & Candida sp. SY16 & 13 \\
\hline & Kurtzmanomyces sp. I-11 & 14 \\
\hline & Pseudozyma fusifornata, & 15 \\
\hline & P. parantarctica, & \\
\hline & P. tsukubabaensis & \\
\hline & P. rugulosa & 16 \\
\hline & P. aphidis & 17 \\
\hline \multirow[t]{5}{*}{$\begin{array}{l}\text { Complexo carboidrato - } \\
\text { proteína - lipídeo }\end{array}$} & $\begin{array}{c}\text { Yarrowia lipolytica IMUFRJ } \\
50682\end{array}$ & 18 \\
\hline & Yarrowia lipolytica NCIM 3589 & 19 \\
\hline & Debaryomyces polymorphus & 20 \\
\hline & Candida tropicalis & 20 \\
\hline & Candida lipolytica IA 1055 & 21 \\
\hline $\begin{array}{l}\text { Complexo carboidrato - } \\
\text { proteína }\end{array}$ & Candida lipolytica ATCC 8662 & 22 \\
\hline Ácido graxo & Candida ingens & 23 \\
\hline \multirow[t]{3}{*}{$\mathrm{ND}^{\mathrm{a}}$} & Candida utilis & 4 \\
\hline & Candida valida & 4 \\
\hline & Candida boleticola & 24 \\
\hline Polióis - lipídeos & $\begin{array}{l}\text { Rhodotorula glutinis, } \\
\text { Rhodotorula graminis }\end{array}$ & 25 \\
\hline
\end{tabular}

${ }^{a}$ ND não determinado

Tabela 2. Diferentes formas de produção de biossurfactante ${ }^{34}$

Produção de biossurfactante associado ao crescimento celular Indução da produção por substratos lipofílicos

Aumento da produção por otimização da composição do meio Aumento da produção por otimização das condições de $\mathrm{pH}$, aeração, velocidade de agitação, etc

Aumento da produção por adição de reagentes, o que causa uma mudança na permeabilidade da parede celular, como penicilina e EDTA

Produção de biossurfactante por crescimento celular em condições limitantes

de nitrogênio

de cátions multivalentes

por mudanças no ambiente do meio, como $\mathrm{pH}$ e temperatura

Produção de biossurfactante por resting cell

Produção por células livres

Produção por células imobilizadas

Produção por células imobilizadas com remoção simultânea do produto

Produção de biossurfactantes por crescimento associado e resting cells com adição de precursores

\section{FATORES QUE AFETAM A PRODUÇÃO DE BIOSSURFACTANTE}

A composição e as características dos biossurfactantes produzidos por microorganismos são influenciadas pela natureza das fontes de carbono e nitrogênio utilizadas, assim como pela presença de fósforo, ferro, manganês e magnésio no meio de produção. Além disso, outros fatores, como $\mathrm{pH}$, temperatura, agitação e forma de condução do processo são extremamente importantes na quantidade e na qualidade do biossurfactante produzido. ${ }^{31}$ Para obtenção de grande quantidade de biossurfactante é de fundamental importância o estudo dos requerimentos nutricionais e das condições do processo.

A produção de biossurfactante pode ser espontânea ou induzida pela presença de compostos lipofílicos, por variações de $\mathrm{pH}$, temperatura, aeração e velocidade de agitação, ou ainda, quando o crescimento celular é mantido sob condições de estresse, como baixas concentrações da fonte de nitrogênio. ${ }^{1}$ A Tabela 2 apresenta diferentes possibilidades de produção de biossurfactantes.

A produção de biosurfactantes por resting cells é uma forma de produção em que não há multiplicação celular. Contudo, as células continuam a utilizar a fonte de carbono para produção do biossurfactante. ${ }^{1} \mathrm{Na}$ literatura há alguns exemplos de produção de biossurfactantes por resting cells de leveduras, como a produção de manosileritritol por Candida antarctica ${ }^{12}$ e produção de soforolipídeos por Torulopsis bombicola $^{9,32}$ e Candida apícola ${ }^{33}$ dentre outros.

\section{A fonte de carbono}

A influência da fonte de carbono na produção de biossurfactante por diferentes cepas de microorganismos tem sido bastante estudada. A literatura aponta uma ampla diversidade entre as fontes de carbono. Pareilleux ${ }^{35}$ isolou compostos tenso-ativos a partir da levedura Candida lipolytica em meio contendo $n$-alcanos como fonte de carbono, mas quando foi cultivada em meio contendo glicose a levedura não produziu nenhum bioemulsificante. Em um estudo similar, Zinjarde e Pant ${ }^{19}$ mostraram que a biossíntese de surfactante por $Y$. lipolytica NCIM 3589 utilizando como fonte de carbono substratos solúveis (glicose, glicerol, acetato de sódio e álcool) não é viabilizada. Entretanto, em meio contendo óleo cru e alcanos $\left(\mathrm{C}_{10}-\mathrm{C}_{18}\right)$ detectou-se a produção de bioemulsificante. Observações similares foram obtidas por Kim e Rehm. ${ }^{36}$

Cirigliano e Carmam ${ }^{22}$ mostraram que a levedura $Y$. lipolytica produz biossurfactantes a partir de diferentes fontes de carbono, tais como hexadecano, parafina, óleo de soja, óleo de oliva, óleo de milho e óleo de algodão, sendo que com hexadecano houve maior produção de biossurfactante.

Em 2001, Sarubbo et al.$^{30}$ produziram biossurfactante utilizando glicose como fonte de carbono a partir da levedura $C$. lipolytica IA 1055, o qual apresentou uma alta atividade de emulsificação. Estes autores mostraram que não é necessária a presença de hidrocarbonetos para indução da biossíntese de surfactantes.

Amaral et al. ${ }^{18}$ utilizaram também como fonte de carbono a glicose para a síntese do biossurfactante denominado Yansan, a partir de $Y$. lipolytica IMUFRJ 50682. Yansan apresentou alta atividade de emulsificação e capacidade de estabilização de emulsões óleo/água. Adicionalmente, meios de cultura contendo lactose como substrato foram utilizados para a produção de manoproteínas, com propriedades emulsificantes, pela levedura $K$. marxianus. ${ }^{6}$

Apesar da produção de biossurfactantes ocorrer na presença de fontes de carbonos solúveis em água, como os açúcares, vários estudos mostram que as maiores produções de biossurfactantes são obtidas quando substratos hidrofóbicos são adicionados. ${ }^{37}$ Muitos trabalhos descrevem a importância da combinação entre um substrato insolúvel 
em água e um carboidrato, como constituintes do meio de cultura.

Os substratos hidrofílicos são utilizados primeiramente pelo microorganismo para o metabolismo celular e para a síntese da porção polar da molécula de biossurfactante, enquanto que os substratos hidrofóbicos são utilizados exclusivamente para a produção da porção hidrocarbônica do biossurfactante. As espécies de Candida são capazes de incorporar diretamente ácido graxo para a produção de biossurfactante..$^{38}$

As vias metabólicas envolvidas na síntese de precursores para produção de biossurfactante são diversas e dependem da natureza da principal fonte de carbono utilizada no meio de cultivo. Por exemplo, quando se utiliza carboidratos como única fonte de carbono no meio de cultivo para a produção de glicolipídeo, o fluxo de carbono é regulado de tal forma que ambas as vias lipogênicas (formação de lipídeos) e de formação da porção hidrofílica (através da via glicolítica) são especialmente supridas pelo metabolismo microbiano, como mostra a Figura 2.

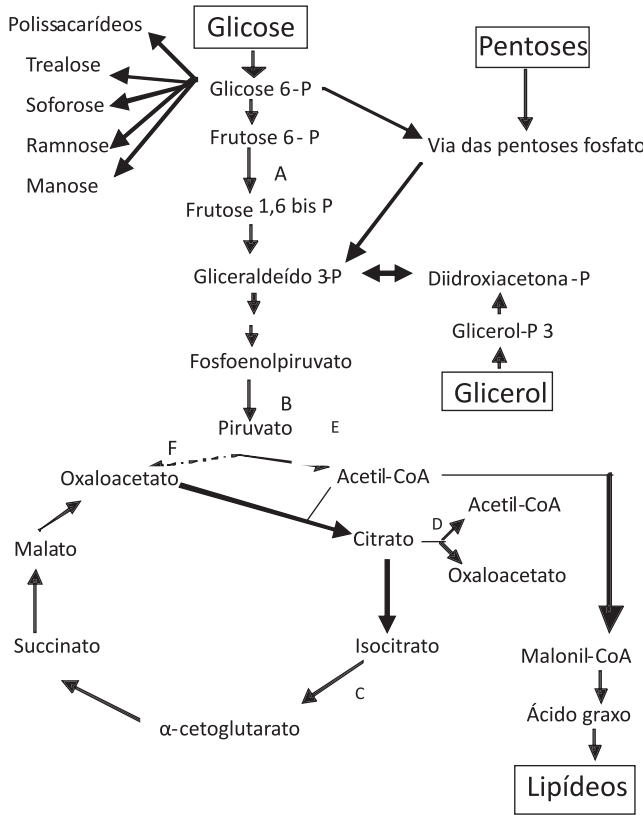

Figura 2. Metabolismo intermediário relacionado à síntese de precursores de biossurfactante a partir da utilização de carboidratos como substratos. Enzimas chaves para o controle do fluxo de carbono: A. fosfofrutoquinase; B. Piruvato quinase; C. isocitrato desidrogenase; D. citrato liase (presentes apenas em leveduras oleaginosas e fungos). E: piruvato desidrogenase; $F$ : piruvato carboxilase. ${ }^{34}$

O substrato hidrofílico utilizado, como por exemplo a glicose, glicerol ou outros, é degradado até formar intermediários da via glicolítica, como a glicose 6-fosfato que é um dos principais precursores dos carboidratos presentes na porção hidrofílica do biossurfactante (Figura 2). Para a produção de lipídeos a glicose é oxidada a piruvato por meio da glicólise, sendo o piruvato então convertido a acetil-CoA, que unida ao oxaloacetato produz malonil-CoA e, em seguida, ácido graxo, um dos precursores para a síntese de lipídeos. ${ }^{34}$

Por outro lado, quando um hidrocarboneto é utilizado como fonte de carbono o metabolismo microbiano se dirige principalmente à via lipolítica e à gliconeogênese (formação de glicose a partir de precursores diferentes das hexoses) podendo, desta forma, ser utilizado para produzir ácidos graxos ou sacarídeos. Para a produção dos sacarídeos a via da gliconeogênese é ativada. Consiste na oxidação dos ácidos graxos via $\beta$-oxidação a acetil-CoA (ou propionil-CoA, no caso de ácidos graxos de cadeia ímpar). A partir da formação do acetil-CoA, as reações envolvidas na síntese dos precursores do polissacarídeo, tal como glicose 6-fosfato, são essencialmente o inverso daquelas envolvidas na glicólise. Entretanto, as reações catalisadas pela piruvato quinase e fosfofrutoquinase-1 são irreversíveis; desta forma, outras enzimas, as quais são exclusivas para gliconeogênese, são requeridas para contornar tais reações. As principais reações são apresentadas na Figura 3, até a formação da glicose 6-fosfato que é a principal precursora dos polissacarídeos, dissacarídeos a serem formados para produção da porção hidrofílica dos glicolipídeos.
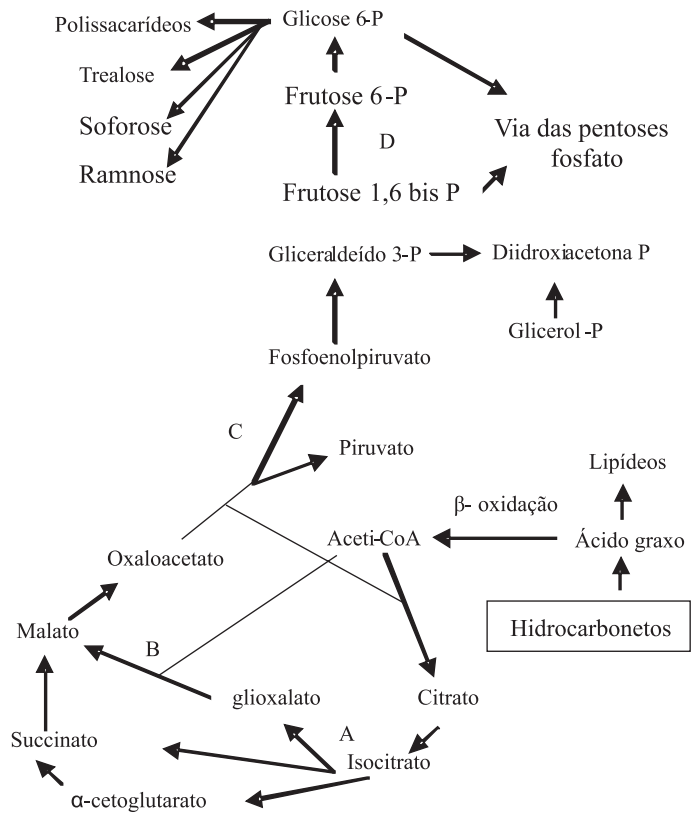

Figura 3. Metabolismo intermediário relacionado à síntese de precursores de biossurfactante a partir da utilização de hidrocarbonetos como substratos. As enzimas chaves são: A. isocitrato liase; B. malato sintase; C. fosfoenolpiruvato carboxilase; D. frutose - 1,6 bifosfatase. ${ }^{34}$

De acordo com Sydatk e Wagner, ${ }^{34}$ a biossíntese do emulsificante pode acontecer seguindo quatro caminhos diferentes: síntese do carboidrato e do lipídeo; síntese da metade de carboidrato, enquanto que a síntese da metade lipídica dependerá do comprimento da cadeia do substrato carbônico presente no meio; síntese da metade lipídica, enquanto que a síntese da metade de carboidrato dependerá do substrato utilizado; síntese das metades carboidrato e lipídica, dependendo do substrato.

Portanto, um fator que altera a biossíntese do surfactante é o comprimento da cadeia do $n$-alcano utilizado como fonte de carbono. Kitamoto et al. ${ }^{40}$ estudaram a produção de lipídeos de manosileritritol (Mel) pela levedura Candida antarctica frente a diferentes $n$-alcanos. Observou-se que essa espécie não cresce e nem produz biossurfactante em meio contendo $n$-alcanos de $\mathrm{C}_{10} \mathrm{a} \mathrm{C}_{18}$. Entretanto, quando cultivada em meio contendo $n$-alcanos de $C_{12}$ a $C_{18}$ houve produção, sendo que o octadecano foi o substrato que promoveu maior rendimento. Já em meio contendo $n$-alcanos com números de carbono maiores que 19 a produção foi mínima.

A produção de manosileritritol lipídeo por $C$. antarctica, utilizando a metodologia resting cell, também foi significativamente afetada pelo comprimento da cadeia carbônica do substrato utilizado, sendo que o maior rendimento foi obtido utilizando pentadecano como fonte de carbono. ${ }^{12}$

Cavalero e Cooper ${ }^{41}$ também mostraram que o rendimento da produção de biossurfactante aumenta com o aumento do comprimento da cadeia do $n$-alcano utilizado $\left(\mathrm{C}_{12}\right.$ para $\left.\mathrm{C}_{15}\right)$. Entretanto, Zinjarde e Pant ${ }^{19}$ demonstraram que a produção de biossurfactante por $Y$. lipolytica foi similar quando se alterou o comprimento da cadeia do 
n-alcano utilizado como substrato.

Candida glabrata foi avaliada para a produção de biossurfactantes a partir de óleo de algodão e glicose. Utilizou-se um planejamento fatorial, do qual se concluiu, com um nível de $95 \%$ de confiança, que apenas a concentração de glicose produziu um efeito positivo sobre o aumento do índice de emulsificação. ${ }^{42}$

Casas e Ochoa ${ }^{9}$ estudaram a composição do meio de produção de soforolipídeos por Candida bombicola. As fontes de carbono que promoveram maior produção de biossurfactante foram glicose (100 g/L) juntamente com óleo de girassol (100 g/L), obtendo-se uma concentração de $120 \mathrm{~g} / \mathrm{L}$ de biossurfactante após 144 h de fermentação.

Farias e Sarubbo ${ }^{43}$ otimizaram as condições de produção do biossurfactante por $C$. lipolytica em meio contendo óleo de canola $(100 \mathrm{~g} / \mathrm{L})$ e glicose $(100 \mathrm{~g} / \mathrm{L})$. O biossurfactante produzido foi capaz de reduzir a tensão superficial de $71 \mathrm{mN} / \mathrm{m}$ para valores em torno de $30 \mathrm{mN} / \mathrm{m}$.

Vários óleos vegetais (milho, soja, açafrão e girassol) foram utilizados como substrato para a produção de biossurfactante por Torulopsis bombicola. O rendimento do biossurfactante foi praticamente igual em todos os óleos. ${ }^{10}$

\section{Fontes de carbono de origens renováveis}

A utilização industrial dos biossurfactantes tem sido dificultada devido aos altos custos de produção associados ao uso de substratos dispendiosos. Por outro lado, estes custos podem ser significativamente reduzidos pelo uso de fontes alternativas de nutrientes, com baixo custo, bem como através da obtenção de altos rendimentos em produtos. ${ }^{44}$ Uma possível solução seria o reaproveitamento de subprodutos industriais como, por exemplo, aqueles provenientes da agroindústria.

Essa estratégia diminui os custos da produção do biossurfactante e, conseqüentemente, reduz a poluição causada por esses rejeitos quando lançados no meio ambiente. ${ }^{45} \mathrm{~A}$ maioria das indústrias alimentícias utiliza gorduras e óleos, gerando grandes quantidades de resíduos graxos. Com o acúmulo desses resíduos, tem aumentado o interesse na utilização desses materiais como fonte de nutrientes para transformação microbiana. ${ }^{46}$

Thanomsub et al..$^{47}$ utilizaram como fonte de carbono o óleo de soja queimado, proveniente da fritura, para produção de um biossurfactante glicolipídico a partir de Candida ishwadae. Este surfactante exibiu alta atividade de emulsificação.

Bednarski et al. ${ }^{48}$ com o objetivo de avaliar a utilização de rejeitos gordurosos, empregaram o soapstock (resíduo da fábrica de sabão) como fonte de carbono para indução da biossíntese de glicolipídeos por leveduras (C. antarctica ATTCC 20509 e C. apicola ATCC 96134). Os autores mostraram que a eficiência na síntese de glicolipídeos por leveduras utilizando soapstock foi 7,5 a 8,3 vezes melhor que em meio não suplementado com soapstock.

O resíduo da refinaria de óleo vegetal de soja e a milhocina (resíduo industrial do processamento de milho) foram utilizados como substratos de baixo custo para a produção de biossurfactante por Candida sphaerica. Os resultados obtidos demonstraram que o melhor rendimento em biossurfactante foi obtido em meio de cultivo contendo 5\% de resíduo de óleo vegetal e 2,5\% de milhocina. ${ }^{49}$

Similarmente, Almeida et al. ${ }^{50}$ utilizaram como substrato o resíduo de óleo e a milhocina, e por meio de planejamento fatorial demonstraram que a milhocina apresenta um resultado positivo, enquanto que o resíduo de óleo apresenta um efeito negativo.

A manipueira, água gerada na prensagem da mandioca, com alto teor de toxicidade para o meio ambiente, foi utilizada como fonte de carbono para a produção de biossurfactante por $C$. lipolytica. Neste estudo foi realizado um planejamento fatorial completo para avaliar estatisticamente os principais efeitos entre as variáveis: concentração de manipueira, de sulfato de amônio e de uréia. De acordo com os resultados, a redução da tensão superficial foi significativa em maior concentração de manipueira (10\%) e menor concentração de sulfato de amônio e uréia. ${ }^{51}$

C. glabrata foi cultivada em resíduo da indústria de fabricação de margarina (gordura vegetal) para a produção de biossurfactante. Já nas primeiras $24 \mathrm{~h}$ de cultivo, houve uma redução da tensão superficial do meio de 71 para $27 \mathrm{mN} / \mathrm{m}$, permanecendo constante até o final das $144 \mathrm{~h}$ de fermentação. ${ }^{52}$

A produção de soforolipídeos por $C$. bombicola foi estimulada pela adição de gordura animal, um resíduo das indústrias de processamento de carne, obtendo-se uma alta produção do biossurfactante $(120 \mathrm{~g} / \mathrm{L})$ em $68 \mathrm{~h}$ de fermentação. ${ }^{53}$

Uma fonte de carbono de origem renovável, importante atualmente, é o glicerol. O crescimento da produção mundial de biodiesel está gerando um excedente de glicerol, subproduto da fabricação do biocombustível. Os preços estão diminuindo, e tendem a diminuir mais, porque os mercados tradicionais do glicerol têm uma capacidade limitada de absorção de quantidades maiores do produto. $\mathrm{O}$ processo produtivo gera em média, para cada $10 \mathrm{~kg}$ de biodiesel, 1 $\mathrm{kg}$ de glicerol..$^{54}$

Morita et al. ${ }^{55}$ utilizaram glicerol para produção de glicolipídeos pela levedura Pseudozyma antarctica, obtendo um rendimento de 16,3 g/L do biossurfactante após 7 dias de cultivo. A biossíntese de soforolipídeo por $C$. bombicola foi também realizada utilizando-se subproduto da produção do biodiesel, composto por $40 \%$ de glicerol, $34 \%$ de compostos solúveis em hexadecano (92\% de ácido graxo e $6 \%$ de monoalcilglicerol/triacilglicerol) e $26 \%$ de água. O rendimento da produção de soforolipídeo foi de $60 \mathrm{~g} / \mathrm{L} .{ }^{56}$

O melaço de soja, um subproduto da produção de óleo de soja, e o ácido oléico foram utilizados como fonte de carbono para a produção de soforolipídeos pela levedura $C$. bombicola. Os autores reportaram um rendimento de $21 \mathrm{~g} / \mathrm{L}$ após 7 dias de fermentação, um valor baixo quando comparado com a utilização de glicose e ácido oléico $(79 \mathrm{~g} / \mathrm{L}) .^{57}$

O óleo de pequi (Caryocar coriaceum camb.) extraído da semente de pequi foi utilizado como fonte de carbono para produção de biossurfactante por $C$. lipolytica. Um planejamento fatorial completo foi realizado, com 7 condições diferentes, visando a otimização do meio de produção, com diferentes combinações entre o óleo de pequi e a glicose. Após 48 h de cultivo, a menor tensão superficial do meio de produção foi de $31,96 \mathrm{mN} / \mathrm{m}$, observando-se uma redução de $60 \%$ quando comparada à tensão superficial da água. ${ }^{58}$

\section{Fonte de nitrogênio}

No meio de produção de biossurfactantes o nitrogênio é essencial para o crescimento celular, sendo de grande importância para a síntese de proteínas e enzimas. Diferentes compostos nitrogenados têm sido empregados na produção de biossurfactantes, tais como licor de milho, milhocina, ${ }^{58}$ uréia, ${ }^{21}$ peptona, ${ }^{13}$ extrato de levedura, ${ }^{8,9,23,59}$ sulfato de amônio, ${ }^{19}$ nitrato de amônio,${ }^{47}$ nitrato de sódio, ${ }^{48}$ dentre outros como extrato de carne, farelo de soja e extrato de malte. ${ }^{60}$ $\mathrm{O}$ extrato de levedura é a fonte de nitrogênio mais utilizada para a produção de biossurfactantes, mas sua concentração varia de acordo com o microorganismo e o meio de produção.

Coopper e Paddock ${ }^{10}$ estudaram o efeito da fonte de nitrogênio, tais como nitrato de sódio, cloreto de amônio, nitrato de amônio, $\left(\mathrm{NH}_{2}\right)_{2} \mathrm{CO}$ e extrato de levedura, na produção de biossurfactante por T. bombicola em frascos agitados. Observaram que o nitrato não é uma boa fonte de nitrogênio, pois apresentou redução na produção da biomassa. Já com o extrato de levedura, na concentração de $5 \mathrm{~g} / \mathrm{L}$, 
houve melhor produção de biossurfactante. Quando se substituiu o extrato de levedura por peptona, a concentração obtida de biossurfactante foi reduzida à metade e quando esta foi substituída por uréia a produção de biossurfactante foi muito baixa.

A produção de bioemulsificante por $Y$. lipolytica foi avaliada frente a diferentes fontes de nitrogênio: sulfato de amônio, cloreto de amônio, nitrato de amônio, uréia e nitrato de sódio. Os resultados mostraram que sulfato de amônio e cloreto de amônio foram as fontes de nitrogênio que propiciaram maior atividade de emulsificação, enquanto que esta atividade foi reduzida à metade quando se utilizou nitrato de amônio e uréia. Não foi detectada atividade de emulsificação quando o nitrato de sódio foi utilizado. ${ }^{19}$

Casas e Ochoa, ${ }^{9}$ para otimizar o meio de produção, testaram diferentes concentrações de extrato de levedura ( 1 a 20 g/L) e observaram que em baixas concentrações de extrato de levedura $(1 \mathrm{~g} / \mathrm{L})$ a produção de soforolipídeos produzidos por Candida bombicola é favorecida. Segundo os autores, em altas concentrações de extrato de levedura, a produção de biossurfactante diminui, devido à exaustão da fonte de carbono, causada pelo grande crescimento da biomassa.

Johnson ${ }^{61}$ relatou a influência da fonte de nitrogênio na produção de biossurfactante pela levedura Rhodotorula glutinis IIP-30, tendo o nitrato de potássio apresentado o melhor desempenho em relação às outras fontes utilizadas (sulfato de amônio e uréia).

Como mostra a literatura, vários pesquisadores optam por utilizar mais de um tipo de fonte de nitrogênio, obtendo boas concentrações de biossurfactante. Vance-Harrop et al. ${ }^{62}$ utilizaram como fonte de nitrogênio sulfato de amônio $(0,1 \%)$ juntamente com uréia $(0,1 \%)$ para a produção de biossurfactante por $C$. lipolytica, detectando alta atividade de emulsificação.

Lukondeh et al. ${ }^{6}$ realizaram fermentações para a produção do bioemulsificante produzido por Kluyveromyces marxianus FII 510700, utilizando como fonte de nitrogênio extrato de levedura ( $2 \mathrm{~g} / \mathrm{L})$ e sulfato de amônio ( $5 \mathrm{~g} / \mathrm{L})$. O bioemulsificante resultante apresentou alta atividade de emulsificação (76\% de fase emulsionada após 90 dias a $4^{\circ} \mathrm{C}$ ).

Com o objetivo de aperfeiçoar o meio de produção do bioemulsificante por $C$. lipolytica, Albuquerque et al. ${ }^{63}$ utilizaram planejamento fatorial para investigar efeitos e interações das concentrações de uréia, sulfato de amônio, di-hidrogênio fosfato de potássio e óleo de milho na atividade de emulsificação. A presença de $\mathrm{KH}_{2} \mathrm{PO}_{4},\left(\mathrm{NH}_{4}\right)_{2} \mathrm{SO}_{4} \mathrm{e}$ óleo de milho teve uma influência positiva na atividade de emulsificação. Por outro lado, a uréia teve uma influência negativa.

A produção de biossurfactante ocorre principalmente quando a fonte de nitrogênio está esgotada, durante a fase estacionária do crescimento da biomassa. ${ }^{13}$ A Figura 4 apresenta o crescimento celular da levedura $C$. antarctica em batelada, em meio contendo íon amônio $(10 \mathrm{~g} / \mathrm{L})$ e peptona $(1 \mathrm{~g} / \mathrm{L})$ como fontes de nitrogênio. Observa-se

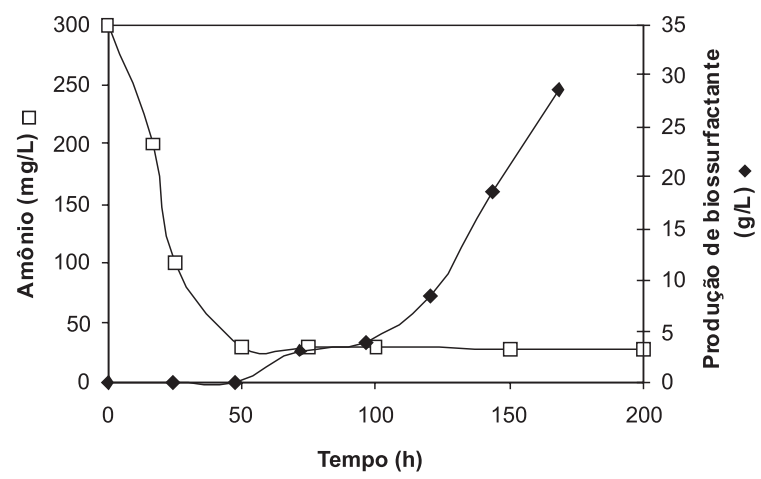

Figura 4. Cultivo de Candida antarctica mostrando o consumo de nitrogênio (amônio) e o início da produção do biossurfactante MEL-SY16 que a produção do glicolipídeo ocorre quando há o esgotamento da fonte de nitrogênio (entre 50 e $200 \mathrm{~h}$ ), atingindo um valor de $38 \mathrm{~g} / \mathrm{L}$ após $200 \mathrm{~h}$ de fermentação. ${ }^{13}$

Albrecht et al..$^{64}$ sugeriram um mecanismo pelo qual a síntese de biossurfactante acontece em condições limitantes de nitrogênio. Segundo os autores, esta condição causa um declínio na atividade específica da isocitrato desidrogenase (dependente de $\mathrm{NAD}^{+}$e $\mathrm{NADP}^{+}$), enzima responsável pela oxidação do isocitrato a $\alpha$ - cetoglutarato no ciclo do ácido cítrico. Como o declínio da atividade leva a um acúmulo de isocitrato e subseqüente citrato na mitocôndria, ambos são transportados para dentro do citosol, onde o citrato é clivado pela citrato sintase, originando acetil-coA, que é o precursor da síntese de ácido graxo aumentando, dessa forma, a produção de biossurfactante.

Um parâmetro bastante estudado pelos pesquisadores é a relação quantitativa entre as fontes de carbono e nitrogênio utilizadas para a produção de biossurfactante. Foi estudado o efeito de diferentes relações $\mathrm{C} / \mathrm{N}$ na produção do bioemulsificante produzido por Rhodotorula glutinis, utilizando diferentes hidrocarbonetos. A atividade de emulsificação aumentou com o aumento da relação $\mathrm{C} / \mathrm{N}$ na maioria dos casos, sendo esse aumento observado em condições limitantes de nitrogênio. ${ }^{51}$ Observações similares foram obtidas com C. tropicalis. ${ }^{65}$

A Tabela 3 resume alguns dados da produção de biossurfactante por leveduras, apresentando as concentrações das fontes de carbono e nitrogênio utilizadas no meio de cultivo. Coeficientes de rendimento $\left(\mathrm{Y}_{\mathrm{P} / \mathrm{S}}\right.$ ) de 0,012 a $0,675 \mathrm{~g} / \mathrm{g}$ e valores de produtividade volumétrica $\left(Q_{\mathrm{P}}\right)$ entre 0,021 e $1,76 \mathrm{~g} / \mathrm{L} \mathrm{h}$ têm sido relatados na produção de biossurfactante por levedura.

\section{Forma de condução do processo}

Após a otimização do meio de cultivo, diferentes formas de condução de processos para obtenção de biossurfactantes têm sido descritas na literatura, de maneira a incrementar a produção desses.

De forma geral, um processo pode ser operado das seguintes formas: ${ }^{34}$ descontínuo (com um inóculo por tanque; com recirculação de células); semicontínuo (batelada alimentada - com ou sem recirculação de células); descontínuo alimentado (batelada simples com ou sem recirculação de células; contínuo (conduzido em um ou em vários reatores; com ou sem recirculação de células).

Entre as opções supracitadas, as fermentações por batelada simples e batelada alimentada são as mais utilizadas para estudos de produção de biossurfactante por leveduras (Tabela 3 ).

Os cultivos por batelada e batelada alimentada são modos de condução de bioprocessos, cujas características tornam suas aplicações atrativas para uma grande gama de processos fermentativos, por exigirem menos em termos de equipamentos, acompanhamento e manutenção. São também mais seguros em relação ao problema da manutenção das condições de assepsia, pois ao final de cada batelada o reator é esterilizado juntamente com o novo meio de cultura, recebendo um novo inóculo, com todos os controles necessários, a fim de assegurar a presença única do microorganismo responsável pelo processo. ${ }^{34}$

No decorrer do processo por batelada simples nada é adicionado, exceto oxigênio no caso de processos aeróbicos, anti-espumante e ácido ou base para controle do $\mathrm{pH}$. Entretanto, durante a batelada alimentada os nutrientes, ou parte deles, são adicionados ao biorreator por uma corrente de alimentação que, por não existir descarga, provoca um contínuo incremento do volume ocupado no reator. Normalmente, esta forma de condução de bioprocessos é utilizada em sistemas nos quais o agente microbiano seja fortemente sensível a fenômenos de inibição por substrato, ou repressão catabólica, tipicamente manifestados em sistemas que apresentem cinética de 
Tabela 3. Dados de estudos da produção de biossurfactantes produzidos por leveduras, registrados na literatura

\begin{tabular}{|c|c|c|c|c|c|c|c|c|c|c|}
\hline Cepa & Fonte C (g/L) & Fonte $\mathrm{N}(\mathrm{g} / \mathrm{L})$ & $\mathrm{PB}^{\mathrm{a}}$ & $\mathrm{T}^{\mathrm{b}}(\mathrm{h})$ & $\begin{array}{l}\text { Modo de } \\
\text { condução }\end{array}$ & $\mathrm{Y}_{\mathrm{P} / \mathrm{S}}(\mathrm{g} / \mathrm{g})$ & $\mathrm{X}^{\mathrm{c}}(\mathrm{g} / \mathrm{L})$ & $\mathrm{Y}_{\mathrm{P} / \mathrm{X}}^{\mathrm{d}}(\mathrm{g} / \mathrm{g})$ & $\mathrm{Qp}(\mathrm{g} / \mathrm{L} \mathrm{h})$ & Ref. \\
\hline $\begin{array}{l}\text { T. bombicola } \\
\text { ATCC22214 }\end{array}$ & $\begin{array}{c}\text { Glicose (500) } \\
\text { Óleo de açafrão } \\
(1000)\end{array}$ & Ext. levedura (5) & $18(\mathrm{~g} / \mathrm{L})$ & 48 & Batelada & 0,012 & 12,4 & 1,45 & 0,375 & 10 \\
\hline $\begin{array}{l}\text { C. bombicola } \\
\text { ATCC } 22214\end{array}$ & $\begin{array}{c}\text { Glicose (100) } \\
\text { Gordura animal } \\
(100)\end{array}$ & $\begin{array}{l}\operatorname{CSL}^{\mathrm{e}}(4) \\
\text { Uréia }(1,5)\end{array}$ & $120(\mathrm{~g} / \mathrm{L})$ & 68 & Batelada & 0,6 & 30 & 4 & 1,76 & 53 \\
\hline $\begin{array}{l}\text { C. tropicalis } \\
\text { ATCC20336 } \\
\end{array}$ & Hexadecano (10) & $\begin{array}{c}\text { Ext. levedura }(0,3) \\
\text { Peptona }(0,5) \\
\end{array}$ & $0,81 \mathrm{U}$ & 72 & Batelada & $N^{f}$ & ND & ND & ND & 20 \\
\hline $\begin{array}{l}\text { D. polymorphus } \\
\text { ATCC20499 }\end{array}$ & Hexadecano (10) & $\begin{array}{c}\text { Ext. levedura }(0,3) \\
\text { Peptona }(0,5)\end{array}$ & $0,11 \mathrm{U}$ & 72 & Batelada & ND & ND & ND & ND & 20 \\
\hline $\begin{array}{l}\text { Candida sp. } \\
\text { SY } 16 \\
\end{array}$ & $\begin{array}{c}\text { Glicose (15) } \\
\text { Óleo de soja (15) }\end{array}$ & Peptona (1) & $95(\mathrm{~g} / \mathrm{L})$ & 200 & $\begin{array}{c}\text { Batelada } \\
\text { alimentada } \\
\end{array}$ & 0,475 & 15,0 & 6,33 & 0,475 & 13 \\
\hline $\begin{array}{l}\text { Candida } \\
\text { bombicola }\end{array}$ & $\begin{array}{c}\text { Glicose (100) } \\
\text { Óleo de girassol } \\
(100)\end{array}$ & Ext. levedura (1) & $120(\mathrm{~g} / \mathrm{L})$ & 192 & $\begin{array}{c}\text { Batelada } \\
\text { Resting cell }\end{array}$ & 0,6 & 23,0 & 5,21 & 0,625 & 9 \\
\hline $\begin{array}{l}\text { C. antarctica } \\
\text { ATCC20509 }\end{array}$ & Óleo de soja (80) & Ext. levedura (1) & $46(\mathrm{~g} / \mathrm{L})$ & 144 & Batelada & 0,57 & 28,4 & 1,61 & 0,32 & 59 \\
\hline $\begin{array}{l}\text { C. antarctica } \\
\text { ATCC20509 }\end{array}$ & Soapstock (100) & $\begin{array}{c}\text { Ext. levedura (1) } \\
\mathrm{NaNO}_{3}(2)\end{array}$ & $15,9(\mathrm{~g} / \mathrm{L})$ & 85 & $\begin{array}{c}\text { Batelada } \\
\text { alimentada } \\
\end{array}$ & 0,636 & 1,8 & 8,83 & 0,1870 & 48 \\
\hline $\begin{array}{l}\text { C. antarctica } \\
T-34\end{array}$ & $\begin{array}{c}\text { Óleo de amêndoa } \\
(80)\end{array}$ & Ext. levedura (1) & $47(\mathrm{~g} / \mathrm{L})$ & 144 & $\begin{array}{c}\text { Batelada } \\
\text { Resting cell }\end{array}$ & 0,587 & 24 & 1,95 & 0,326 & 12 \\
\hline $\begin{array}{l}\text { C. antarctica } \\
T-34 \\
\end{array}$ & n- octadecano (60) & $\begin{array}{c}\text { Ext. levedura (1) } \\
\mathrm{NaNO}_{3}(2) \\
\end{array}$ & $40,5(\mathrm{~g} / \mathrm{L})$ & 144 & $\begin{array}{c}\text { Batelada } \\
\text { Resting cell }\end{array}$ & 0,675 & 16 & 2,53 & 0,281 & 40 \\
\hline $\begin{array}{l}\text { Wickerhamiella } \\
\text { Domercqiae } Y_{2 A}\end{array}$ & $\begin{array}{c}\text { Glicose (50) } \\
\text { Óleo de canola } \\
(20)\end{array}$ & Ext. levedura (2) & ND & ND & Batelada & ND & ND & ND & ND & 8 \\
\hline $\begin{array}{l}\text { C. ingens } \\
C B-216 \\
\end{array}$ & $\begin{array}{l}\text { Óleo de milho } \\
(20)\end{array}$ & Ext. levedura (2) & $5,6(\mathrm{~g} / \mathrm{L})$ & 168 & Batelada & 0,28 & 23,9 & 0,234 & 0,033 & 23 \\
\hline $\begin{array}{l}\text { C. lipolitica } \\
\text { ATCC } 8662 \\
\end{array}$ & Hexadecano (10) & Ext. levedura (6) & $1,3 \mathrm{U} / \mathrm{mL}$ & 130 & Batelada & ND & ND & ND & ND & 22 \\
\hline $\begin{array}{l}Y . \text { lipolitica } \\
\text { NCIM3589 } \\
\end{array}$ & Hexadecano (10) & $\left(\mathrm{NH}_{4}\right)_{2} \mathrm{SO}_{4}(5)$ & $3,0 \mathrm{U} / \mathrm{mL}$ & 144 & Batelada & ND & 3 & ND & ND & 19 \\
\hline $\begin{array}{l}\text { C. lipolitica } \\
\text { IA } 1055\end{array}$ & $\begin{array}{c}\text { Óleo de babaçu } \\
(50)\end{array}$ & Uréia $(0,25)$ & $0,66 \mathrm{U} / \mathrm{mL}$ & 60 & $\begin{array}{c}\text { Batelada } \\
\text { alimentada } \\
\end{array}$ & ND & $6 \mathrm{UFC} / \mathrm{mL}$ & ND & ND & 21 \\
\hline $\begin{array}{l}\text { C. lipolitica } \\
\text { IA } 1055\end{array}$ & $\begin{array}{c}\text { Óleo de milho } \\
(50)\end{array}$ & Uréia $(0,1)$ & $\begin{array}{l}0,235 \\
\mathrm{U} / \mathrm{mL}\end{array}$ & 168 & Batelada & ND & $\begin{array}{c}3,5 \mathrm{UFC} / \\
\mathrm{mL}\end{array}$ & ND & ND & 62 \\
\hline $\begin{array}{l}\text { Y. lipolitica } \\
\text { IMUFRJ } 50682\end{array}$ & Glicose (20) & $\begin{array}{c}\text { Peptona }(6,4) \\
\text { Ext. levedura }(10)\end{array}$ & $2,0 \mathrm{U} / \mathrm{mL}$ & 170 & Batelada & ND & ND & ND & ND & 18 \\
\hline $\begin{array}{l}\text { C. lipolitica } \\
\text { UCP0988 }\end{array}$ & $\begin{array}{c}\text { Glicose (100) } \\
\text { Óleo de canola } \\
(100) \\
\end{array}$ & Ext. levedura (2) & $8(\mathrm{~g} / \mathrm{L})$ & 48 & Batelada & 0,04 & ND & ND & 0,166 & 43 \\
\hline $\begin{array}{l}\text { K. marxianus } \\
\text { FII } 510700\end{array}$ & Lactose (40) & $\begin{array}{l}\text { Ext. levedura (2) } \\
\left(\mathrm{NH}_{4}\right)_{2} \mathrm{SO}_{4}(5)\end{array}$ & ND & ND & Batelada & ND & ND & ND & ND & 6 \\
\hline $\begin{array}{l}\text { C. apicola } \\
\text { ATCC } 20509 \\
\end{array}$ & Soapstock (100) & $\begin{array}{c}\text { Ext. levedura (1) } \\
\mathrm{NaNO}_{3}(2)\end{array}$ & $10,3(\mathrm{~g} / \mathrm{L})$ & 144 & Batelada & 0,103 & 6,5 & 9,70 & 0,071 & 48 \\
\hline $\begin{array}{l}\text { C. glabrata } \\
\text { UCP } 1002\end{array}$ & $\begin{array}{c}\text { Glicose (50) } \\
\text { Óleo de semente } \\
\text { de algodão (75) }\end{array}$ & $\begin{array}{c}\text { Ext. levedura (3) } \\
\mathrm{NH}_{4} \mathrm{NO}_{3}(1)\end{array}$ & $10(\mathrm{~g} / \mathrm{L})$ & 144 & Batelada & 0,08 & 18 cél $/ \mathrm{mL}$ & ND & 0,069 & 42 \\
\hline $\begin{array}{l}\text { Candida } \\
\text { ishiwadae }\end{array}$ & $\begin{array}{c}\text { Óleo de soja quei- } \\
\text { mado (40) }\end{array}$ & $\begin{array}{l}\text { Ext. levedura }(0,5) \\
\mathrm{NH}_{4} \mathrm{NO}_{3}(3)\end{array}$ & $0,25 \mu \mathrm{g}$ & 168 & Batelada & ND & ND & ND & ND & 47 \\
\hline $\begin{array}{l}\text { C. sphaerica } \\
\text { UCP } 995\end{array}$ & $\begin{array}{l}\text { Resíduo de óleo } \\
\text { vegetal (50) }\end{array}$ & Milhocina (25) & $3,116(\mathrm{~g} / \mathrm{L})$ & 144 & Batelada & 0,06 & 2,264 & 1,37 & 0,021 & 49 \\
\hline
\end{tabular}

${ }^{\mathrm{a}} \mathrm{PB}$ : produção de biossurfactantes; ${ }^{\mathrm{b}} \mathrm{T}$ : tempo de produção do biosurfactante; ${ }^{\mathrm{c} X} \mathrm{X}$ : concentração de células produzidas; ${ }^{\mathrm{d}} \mathrm{Y}_{\mathrm{P} / \mathrm{X}}$ : coeficiente de rendimento de biosurfactante em relação à concentração celular; ${ }^{\mathrm{e}} \mathrm{CSL}$ : corn steep liquor; ${ }^{\mathrm{f}} \mathrm{ND}$ : não determinado 
formação de produto não associado ao crescimento.

Resultados bastante promissores vêm sendo publicados baseados no uso de batelada alimentada para a produção de biossurfactante. A produção de lipídeos de manosileritritol por $C$. antarctica foi de 95 $\mathrm{g} / \mathrm{L}$ após $200 \mathrm{~h}$ de fermentação por batelada alimentada, utilizando glicose e óleo de soja como fonte de carbono. O rendimento foi 2,6 vezes maior que o rendimento obtido na produção deste por batelada simples $(37 \mathrm{~g} / \mathrm{L}) .{ }^{13}$

Rau et al.${ }^{17}$ produziram biossurfactante por Pseudozyma aphidis utilizando óleo de soja e glicose, em batelada alimentada, obtendo uma alta produção de biossurfactante $(168 \mathrm{~g} / \mathrm{L})$ ao final de 11 dias de fermentação.

Outros modos de condução de processo também foram avaliados. Kim et al..$^{27}$ estudaram a produção de biossurfactante pela levedura T. bombicola, via processo contínuo, com o objetivo de investigar os efeitos da glicose e do óleo de soja no crescimento celular e na produção de biossurfactante.

Deste modo, a escolha adequada da forma de condução do processo é um passo importante, uma vez que pode alterar a produtividade do produto desejado.

\section{Temperatura, pH, aeração e agitação}

O controle e a otimização das condições operacionais como temperatura, agitação, $\mathrm{pH}$ e aeração são fundamentais para o sucesso da ampliação de escala de produção de biossurfactantes, capazes de torná-los economicamente competitivos em relação aos surfactantes químicos.

O efeito do $\mathrm{pH}$ em relação à produção de biossurfactante por $C$. antarctica foi estudado utilizando-se tampão fosfato em diferentes pHs (4-8). Todos os tampões utilizados resultaram em uma diminuição do rendimento da produção do biossurfactante, quando comparados com a água destilada. ${ }^{40}$

Zinjarde e Pant ${ }^{19}$ estudaram a influência do $\mathrm{pH}$ inicial na produção do biossurfactante por Y. lipolytica. Observaram que a maior produção foi obtida em $\mathrm{pH}$ inicial igual a 8,0 , que corresponde ao $\mathrm{pH}$ natural da água do mar.

$\mathrm{O}$ efeito da temperatura na produção de manosileritritol por resting cell e em condições de crescimento celular por $C$. antarctica foi estudado. Em ambos os casos, a maior produção foi observada a 25 ${ }^{\circ} \mathrm{C}$, sendo que por resting cell a produção de biossurfactante ocorreu em uma faixa ampla de temperatura. $\mathrm{O}$ efeito da aeração também foi testado utilizando diferentes volumes de meio $(20-60 \mathrm{~mL}) \mathrm{em}$ um erlenmeyer de $300 \mathrm{~mL}$. O melhor rendimento foi obtido em um volume de $30 \mathrm{~mL}$, que indica uma relação $\mathrm{Vm} / \mathrm{Vf}=0,1$, demonstrando a forte influência da aeração neste sistema. ${ }^{12}$

Aeração e agitação são dois fatores importantes que influenciam na produção de biossurfactante, pois facilitam a transferência de oxigênio da fase gasosa para a fase aquosa ${ }^{66}$ Adamczak e Bednarsk ${ }^{59}$ avaliaram a influência da aeração na síntese de biossurfactante por C. antarctica. A maior produção de biossurfactante $(45,5 \mathrm{~g} / \mathrm{L})$ foi alcançada quando a levedura foi cultivada em meio com uma taxa de aeração de 1 vvm (volume de ar por volume de meio por min) e a concentração de oxigênio dissolvido controlada em $50 \%$ do valor da saturação. Entretanto, quando se alterou a aeração para 2 vvm, houve uma produção intensa de espuma e a produção de biossurfactante decaiu $84 \%$. A formação de espuma não é um fator desejado na produção, uma vez que retira do meio reacional parte do biossurfactante, biomassa e lipídeos.

Guilmanov et al. ${ }^{67}$ investigaram o efeito da aeração, por meio de experimentos em frascos agitados, na produção de soforolipídeos por C. bombicola. O maior rendimento foi obtido com a taxa de aeração entre 50 e $80 \mathrm{mM} \mathrm{O}_{2} / \mathrm{h} \mathrm{h}^{-1}$.
Com o objetivo de ampliar o processo de produção do bioemulsificante por $C$. lipolytica, da escala de frascos para a escala de biorreator, Albuquerque et al. ${ }^{68}$ estudaram os efeitos da agitação e da temperatura na produção de biossurfactante frente a diferentes óleos. Verificou-se que o aumento da temperatura exerceu um efeito negativo significativo sobre as atividades de emulsificação para as emulsões água em hexadecano e água em óleo de milho e, que o aumento da velocidade de agitação produziu um efeito positivo sobre a atividade de emulsificação de água em óleo de canola. As melhores condições de operação para a produção do biossurfactante foram temperatura de $28^{\circ} \mathrm{C}$ e agitação de $300 \mathrm{rpm}$.

A atividade de emulsificação do biossurfactante produzido pelas leveduras Candida tropicalis e Debaryomyces polymorphus não foi alterada, em uma faixa de $\mathrm{pH}$ entre 4 e $11 .{ }^{20}$ Já a produção do bioemulsificante produzido pela levedura Rhodotorula glutinis durante fermentação em batelada alimentada foi significativamente influenciada tanto pela temperatura como pelo $\mathrm{pH}$, sendo as condições ótimas obtidas para a produção à temperatura de $30^{\circ} \mathrm{C}$ e pH 4.

Na mesma direção, Desphande e Daniels ${ }^{53}$ também avaliaram o efeito da temperatura no crescimento de $C$. bombicola e na produção de soforolipídeos. O crescimento celular máximo foi obtido a $30^{\circ} \mathrm{C}$, enquanto que a produção de soforolipídeos foi máxima a $27^{\circ} \mathrm{C}$.

A maioria das fermentações realizadas para produção de biossurfactante ocorre em uma faixa de temperatura de 25 a $30{ }^{\circ} \mathrm{C}$. Existem vários trabalhos na literatura que estudam a influência desse parâmetro. Casas e Garcia-Ochoa ${ }^{9}$ mostraram que as quantidades de soforolipídeo obtidas por C. bombicola em ambas as temperaturas ( 25 e $30^{\circ} \mathrm{C}$ ) foram próximas. A fermentação realizada a $25^{\circ} \mathrm{C}$ apresentou crescimento menor de biomassa e maior taxa de consumo de glicose em comparação à fermentação realizada a $30^{\circ} \mathrm{C}$.

A acidez do meio de produção foi um parâmetro correlacionado com a eficiência da síntese de glicolipídeos por $C$. antarctica e $C$. apicola. Mantendo o pH em 5,5 obteve-se maior produção de glicolipídeos. Contudo, quando não se ajustou o $\mathrm{pH}$ no meio de cultura, obteve-se um efeito negativo na eficiência de síntese. ${ }^{48}$ Um efeito similar foi observado na produção de glicolipídeos por C. antarctica, através de batelada alimentada. O melhor rendimento da produção foi com controle do $\mathrm{pH}$, mantendo-se em 4 , sendo significativamente melhorada quando comparada com a fermentação sem o controle do $\mathrm{pH}{ }^{42}$

\section{CONCLUSÃO}

Nos últimos anos, o aumento no número de publicações na área de produção de biossurfactante por leveduras mostra que essa tecnologia vem ganhando cada vez mais espaço e importância. Porém, a produção de biossurfactante em escala industrial ainda é reduzida, devido aos custos envolvidos em seu processo produtivo.

A otimização do processo fermentativo é o fator chave para melhorar o rendimento da produção e diminuir os custos. Vários são os estudos voltados à influência das fontes de carbono e nitrogênio, mostrando que são parâmetros importantes na produção de biossurfactantes, uma vez que o tipo e a concentração do substrato empregado pode aumentar ou reduzir a síntese do biossurfactante e, até mesmo modificá-lo estruturalmente. São inúmeras as alternativas apresentadas na literatura como fontes de carbono e nitrogênio, desde fontes hidrofílicas (como glicose, lactose, etc) até hidrofóbicas (óleo de soja, hexadecano, etc). As leveduras, mesmo aquelas da mesma espécie, apresentaram respostas diferentes à produção de biossurfactante frente aos diversos meios de cultivo.

Uma estratégia que está sendo bastante utilizada para diminuir os custos da produção é o uso de substratos de origem renovável como fonte de carbono. Tem-se estimado que a utilização destes diminua 
o custo total da produção em 10 a $30 \%$, além de ser uma possível solução para reaproveitamento de resíduos agroindustriais.

Diferentes formas de condução do processo também afetam a produção de biossurfactante. Observou-se que as formas mais utilizadas são a batelada simples e batelada alimentada. O controle e a otimização das condições operacionais, como temperatura, agitação, pH e aeração, também se mostraram fundamentais para aumentar a eficiência da produção, bem como possibilitar a ampliação de escala do processo.

Para o sucesso da ampliação de escala da produção de biossurfactantes por leveduras, capazes de torná-los economicamente competitivos em relação aos surfactantes químicos, são necessários desenvolvimentos acerca dos tópicos abordados nesta revisão, abrindo novas perspectivas para aumentar a eficiência da produção, tornando possível a aplicação industrial desses compostos em um futuro próximo.

\section{REFERÊNCIAS}

1. Desai, J. D.; Banat, I. N.; Microbiol. Mol. Biol. Rev. 1997, 61, 47.

2. Rosenberg, E.; Ron, E. Z.; Appl. Microbiol. Biotechnol. 1999, 52, 154.

3. Gouveia, E. R.; Lima, D. P. A.; Duarte, M. S.; Lima, G. M. S.; Araújo, J. M.; Rev. Biotecnol. Ciênc. Desenvol. 2003, 30, 39.

4. Sheperd, R.; Rockey, J.; Sutherland, I.; Roller, S.; J. Biotechnol. 1995, 40, 207.

5. Barth, G.; Gaillard, C.; FEMS Microbiol. Rev. 1997, 19, 219.

6. Lukondeh, T.; Ashbolt, N. J.; Rogers, P. L.; J. Indust. Microbiol. Biotechnol. 2003, 30, 715 .

7. Cameron, D. R.; Cooper, D. G.; Neufeld, R. J.; Appl. Environ. Microbiol. 1988, 54, 1420 .

8. Jing, C.; Xin, S.; Hui, Z.; Yinbo, Q.; Enzyme Microb. Technol. 2006, 39, 501 .

9. Casas, J.; Ochoa, F. G.; J. Biosci. Bioeng. 1999, 88, 488.

10. Cooper, D. G.; Paddock, D. A.; Appl. Environ. Microbiol. 1984, 46, 1426.

11. Tulloch, A. P.; Spencer, J. F. T.; Deinema, M. H.; Can. J. Chem. 1968, 46,345 .

12. Kitamoto, D.; Fuzishiro, T.; Yanagishita, H.; Nakane, T.; Nakahara, T.; Biotechnol. Lett. 1992, 14, 305.

13. Kim, H. S.; Jeon, J. W.; Kim, B. H.; Ahn, C. Y.; Mock Oh, H.; Yoon, B. D.; Appl. Microbiol. Biotechnol. 2006, 70, 391.

14. Kakugawa, K.; Tamai, M.; Imamura, K.; Miyamoto, K.; Miyoshy, S.; Morinaga, Y.; Suzuki, O.; Miyakawa, T.; Biosci. Biotechnol. Biochem. 2002, 66, 188.

15. Morita, T.; Konish, M.; Fukuoka, T.; Imura, T.; Kitamoto, H. K.; Kitamoto, D.; FEMS Yeast Res. 2006, 7, 286.

16. Morita, T.; Konish, M.; Fukuoka, T.; Imura, T.; Kitamoto, H. K.; Kitamoto, D.; Appl. Microbiol. Biotechnol. 2006, 73, 305.

17. Rau, U.; Nguyen, L. A.; Roeper, H. ; Koch, H. ; Lang, S. ; Appl. Microbiol. Biotechnol. 2005, 68, 607.

18. Amaral, P. F. F.; da Silva, J. M.; Lehocky, B. M., Barros-Timmons A. M. V.; Coelho, M. A. Z.; Marrucho, I. M.; Coutinho, J. A. P.; Process Biochem. 2006, 41,1894.

19. Zinjarde, S. S.; Pant, A.; J. Basic Microbiol. 2002, 42, 67.

20. Singh, M.; Desai, J. D.; Indian J. Experimental Biol. 1989, 27, 224.

21. Vance - Harrop, M. H. V.; Gusmão, N. B.; Takaki, G. M. C.; Br. J. Microbiol. 2003, 34, 120.

22. Cirigliano, M. C.; Carman, G. M.; Appl. Environ. Microbiol. 1984, 48, 747.

23. Amézcua-Vega, C. A.; Varaldo, P. H. M.; García. F.; Leal E. R.; Vázquez, R. R.; Bioresour. Technol. 2007, 98, 237.

24. Moussa, T. A. A.; Ahmed, G. M.; Abdel-hamid, S. M. S.; J. Appl. Sci. Res. 2006, 11, 844 .
25. Yoon, S. H.; Rhee, J. S.; J. Am. Oil Chemists' Soc. 1983, 60, 1281.

26. Cooper, D. G.; Microbiological Sciences 1986, 3, 145.

27. Kim, H. S.; Yoon, B. D.; Choung, D. D.; Katsuragi, H. M. O. T.; Tarui, Y.; Appl. Microbiol. Biotechnol. 1999, 52, 713.

28. Sarubbo, L. A.; Luna, J. M.; Campos-Takaki, G. M.; Eletronic J. Biotechnol. 2006, 9, 400.

29. Ron, E.; Rosenberg, E.; Environ. Microbiol. 2001, 3, 229.

30. Sarubbo, L. A.; Marçal, M. C.; Neves, M. L. C.; Silva, M. P. C.; Porto, A. L. F.; Campos-Takaki, G. M.; Appl. Biochem. Biotechnol. 2001, 95, 59.

31. Banat, I. M.; Bioresour. Technol. 1995, 51, 1.

32. Göbbert, U.; Lang, S.; Wagner, F.; Biotechnol. Lett. 1984, 6, 225.

33. Hommel , R. K.; Huse, K.; Biotechnol. Lett. 1993, 15, 853.

34. Syldatk, C.; Wagner, F.; Biosurfactants and Biotechnology, Marcel Dekker: New York, 1987, cap. 3.

35. Pareilleux, A.; Appl. Microbiol. Biotechnol. 1979, 8, 91.

36. Kim, Y. B.; Rhem, H. J.; Eur. J. Appl. Microbiol. 1982, 19, 112.

37. Hommel, R. K.; Weber, L.; Weiss, A.; Himmelreich, U.; Rike, O.; Kleber, H. P. ; J. Biotechnol. 1994, 33, 147.

38. Weber, L.; Doge, C.; Haufe, G.; Biocatalysis 1992, 5, 267.

40. Kitamoto, D.; Ikegami, T.; Suzuki, G. T.; Sasaki, A.; Tkeyama, Y.; Idemoto, Y.; Koura, Y.; Yanagishita, H.; Biotechnol. Lett. 2001, 23, 1709.

41. Cavalero, D. A.; Cooper, D. G.; J. Biotechnol. 2003, 103, 31.

42. Luna, J. M.; Rufino, R. D.; Gusmão, C. A. B.; Sarubbo, L. A.; CamposTakaki, G. M.; XV Simpósio Nacional de Bioprocessos, Recife, Brasil, 2005

43. Farias, C. B. B.; Sarubbo, L. A.; $3^{a}$ Semana de Integração Universidade Sociedade - $3^{\circ}$ SIUS e $7^{a}$ Jornada de Iniciação Científica, Pernambuco, Brasil, 2006.

44. Gallert, C.; Winter, J.; Naturwissenschaften 2002, 89, 483.

45. Maneerat, S.; J. Sci. Technolol. 2005, 27, 675.

46. Makkar, R. S.; Cameotra, S. S.; Appl. Microbiol. Biotechnol. 2002, 58, 428.

47. Thanomsub, B.; Watcharachaipong, T.; Chotelersak, K.; Arunrattiyakorn, P.; Nitoda, T.; Kanzaki, H.; J. Appl. Microbiol. 2004, 96, 588.

48. Bednarski, W.; Adamczak, M.; Tomasik, J.; Płaszczyk, M.; Bioresour. Technol. 2004, 95, 15.

49. Sobrinho, H. B. S.; Gusmão, C. A. B.; Luna, J. M.; Rufino, R. D.; Salgueiro, A. A.; Sarubbo, L. A.; $1^{\circ}$ Workshop Meio Ambiente, Ciência e tecnologia de mãos dadas para o futuro, Pernambuco, Brasil, 2006.

50. Almeida, R. G.; Gusmão, C. A. B.; Rufino, R. D.; Farias, C. B. B; Sarubbo, L. A.; X Encontro Nacional de Microbiologia Ambiental, Goiânia, Brasil, 2006.

51. Andrade, R. F. S.; Luna, J. M.; Campos-TaKaki, G. M.; Sarubbo, L. A.; $1^{\circ}$ Workshop Meio Ambiente, Ciência e tecnologia de mãos dadas para o futuro, Pernambuco, Brasil, 2006.

52. Gusmão, C. A. B.; Sarubbo, L. A.; X Encontro Nacional de Microbiologia Ambiental, Goiânia, Brasil, 2006.

53. Desphande, M.; Daniels, L.; Bioresour. Technol. 1995, 54, 143.

54. Meesters, P. A. E. P.; Huijberts, G. N. M.; Eggink, G.; Appl. Microbiol. Biotechnol. 1996, 45, 575.

55. Morita, T.; Konish, M.; Fukuoka, T.; Imura, T.; Kitamoto, D.; J. Biosci. Bioeng. 2007, 104,78.

56. Ashby, R. D.; Nunez, A.; Solaiman, D. K. Y.; Foglia, T. A.; J. Am. Oil Chem. Soc. 2005, 9, 625.

57. Solaiman, D. K. Y.; Ashby, R. D.; Nunez, A.; Foglia, T. A.; Biotechnol. Lett. 2004, 26, 1241.

58. Santana, W. J.; Rufino, R. D.; Neto, B. B.; Porto, A. L.; Campos-Takaki, G. M.; Resumo do XXIII Congresso Brasileiro de Microbiologia, Santos, Brasil, 2005.

59. Adamczak, M.; Bednarski, W.; Biotechnol. Lett. 2000, 22, 34.

60. Mata-sandoval, J. C.; Karns, J.; Torrens, A.; Microbiol. Res. 2001, 155 , 249. 
61. Johnson, V.; Singh, M.; Saini, V. S.; Biotechnol. Lett. 1992, 14, 487.

62. Vance-Harrop, M. H. V.; Sarubbo, L. A.; Carneiro Da-cunha, M. G.; Gusmão, N. B.; Takaki, G. M. C.; Revista Symposium 1999, 2, 23.

63. Albuquerque, C. D. C.; Filetti, A. M. F.; Campos-Takaki, G. M.; Can. J. Microbiol. 2006, 52, 575.

64. Albrecht, A.; Rau, U.; Wagner, F.; Appl. Microbiol. Biotechnol. 1996, 46, 67.

65. Singh, M.; Saini, V. S.; Adhikari, D. K.; Desai, J. D.; Biotechnol. Lett. 1990, 12,743 .

66. Schmidell, W. Agitação e aeração em biorreatores. Em Biotecnologia
Industrial: Engenharia Bioquímica; Schmidell, W.; Lima, U. A.; Aquarone, E.; Borzami, W., eds.; Edgard Blucher Ltda: São Paulo, 2001, cap 14.

67. Guilmanov, V.; Ballistreri, A.; Impallomeni, G.; Gross, R. A.; Biotechnol. Bioeng. 2002, 77, 489.

68. Albuquerque, C. D. C.; Fileti, A. M. F.; Campos-Takaki, G. M.; X Encontro Nacional de Microbiologia Ambiental, Goiânia, Brasil, 2006.

69. Van Bogaert, I. N. A.; De Schamphelaire, W.; Develter, D.; Soetaer, W.; Vandamme, E. J.; Yeast 2007, 24, 201. 